\title{
Cincuenta años de Anuario Filosófico
}

Fifty years of Anuario Filosófico

Jaime Nubiola

Departamento de Filosofía

Facultad de Filosofía y Letras

Universidad de Navarra

31009 Pamplona (España)

jnubiola@unav.es

Abstract: The $50^{\text {th }}$ anniversary of an academic journal of philosophy in Spanish is an occasion for reflecting on its past accomplishments and reconsidering its role in the near future. To be philosopher and do philosophy in the $21^{\text {st }}$ century it is necessary to dedicate oneself to the integration of thought and life and to learn how to share this work with others. The technological changes that are now transforming the world of academic publication portend a future in which a wide audience can be reached with relative ease.

Keywords: Academic journal of philosophy, technological transformation of academic publications.
Resumen: La celebración de los 50 años de una revista académica de filosofía en lengua española invita a evaluar el trabajo realizado y a reconsiderar su papel en el futuro próximo. Para ser filósofo y hacer filosofía en el siglo XXI es indispensable empeñarse en articular unitariamente pensamiento y vida y en aprender a compartirlo con los demás. Las transformaciones tecnológicas — que de modo tan importante están afectando a las publicaciones académicas - permiten aventurar un futuro en el que será posible llegar con más facilidad a un público mucho más amplio.

Palabras clave: Revista académica de filosofía, transformación tecnológica de las publicaciones profesionales. 
on este número se abre el volumen número 50 de la revista Anuario Filosófico. Sin duda alguna, la publicación ininterrumpida de una revista de filosofía en lengua española a lo largo de cincuenta años tiene algo de proeza; es, sobre todo, un monumento a la tenacidad inteligente de todos los que a lo largo de ese considerable periodo de tiempo han aunado sus esfuerzos para que fascículo a fascículo la revista viera la luz con admirable puntualidad y acreditada calidad.

En 1968 en el volumen inaugural de Anuario se anunciaba que la revista había sido concebida e iba a ser publicada "como un instrumento y un estímulo para la comunicación y la cooperación científica". Anuario Filosófico se presentaba expresamente como una publicación libre de adscripción a una escuela determinada o a una tradición filosófica particular. Con ello, la revista se hacía eco de una enseñanza constante del fundador de la Universidad de $\mathrm{Na}$ varra, san Josemaría Escrivá, en favor de la libertad para el trabajo filosófico. "En efecto — se decía en aquella presentación- el Anuario Filosófico, lejos de servir a tesis filosófica alguna con exclusión de las demás, trata más bien de fomentar la dignidad científica de la filosofía”. Esta aspiración se acogía al patrocinio de la concepción aristotélica de la filosofía como ciencia buscada, como "zetouméne epistéme hasta las últimas consecuencias, es decir, hasta la humildad de una búsqueda rigurosa, abierta y común".

Desde aquel comienzo programático, Anuario ha vivido paulatinas transformaciones tanto en su periodicidad (anual, semestral y cuatrimestral) como en sus secciones (estudios y bibliografía) y en el carácter de los números (alternando monográficos y misceláneos), pero se ha mantenido fiel a su empeño por la calidad y el interés de sus contenidos y - lo que no es cosa menor en nuestro país- a su tamaño.

De hecho, los primeros 49 volúmenes de Anuario suman un total de 31.301 páginas impresas, que comprenden 1.178 artículos y notas y 1.306 recensiones de libros. Estos datos al por mayor pueden abrumar un poco a quienes nos dedicamos a escribir filosofía, al considerar los millares de horas de trabajo invertidas en esta tarea por parte de tantísimos autores. La pregunta decisiva es, sin duda, 
la de si tanta erudición nos ha hecho mejores. Quizá cabe recordar a este respecto las palabras finales de la famosa conferencia de Husserl en Viena el 10 de mayo de 1935, "la crisis de la existencia europea solo tiene dos salidas: la decadencia de Europa, alienada de su propio sentido racional de la vida, [con la consiguiente] caída en el odio del espíritu y la barbarie, o el renacimiento de Europa desde el espíritu de la filosofía mediante un beroísmo de la razón que supere definitivamente el naturalismo".

Han pasado ochenta años desde aquellas memorables palabras. Europa atravesó la penosa experiencia de una terrible nueva guerra mundial y el horror del Holocausto. Sin embargo, son bastantes los elementos que llevan a pensar que la supuestamente avanzada sociedad occidental sigue hoy en aquella peligrosa situación, caracterizada por una radical desconfianza hacia la razón libre, el pensamiento independiente y, por supuesto, un menosprecio generalizado de las humanidades.

En la mejor estirpe socrática, para ser filósofo y hacer filosofía en el siglo XXI es indispensable empeñarse en articular unitariamente pensamiento y vida y en aprender a compartirlo con los demás. En nuestra vida como filósofos - y para muchos también como profesores de filosofía-, tenemos que tratar de integrar en un único campo de actividad aquellos dos conceptos kantianos de la filosofía, como Schulbegriff(filosofía académica) y Weltbegriff(filosofía vital o mundana). Aprendí de Hilary Putnam que una filosofía viva —al igual que un campo magnético — se alimenta precisamente de la tensión entre esos dos polos: hay que prestar atención, por un lado, a la erudición, a la publicación de trabajos en revistas altamente especializadas como Anuario; pero, por otro, hemos de escuchar también los gritos de la humanidad y tratar de ayudar a nuestros congéneres con soluciones inteligentes, participando personalmente en los debates actuales. Por supuesto, hay una tensión entre ambos polos, pero esta tensión es la que hace que salte la chispa que enciende y da luz y calor. En este sentido, las transformaciones tecnológicas que de modo tan importante están afectando a las publicaciones académicas permiten aventurar un futuro en el que será posible llegar con más facilidad a un público todavía mucho más amplio. 
Para celebrar el cincuentenario de la revista, el Consejo de Redacción ha decidido reunir en este volumen conmemorativo diez artículos particularmente destacados que a lo largo de estos años han visto la luz en las páginas de Anuario Filosófico. Son trabajos de G.E.M. Anscombe, Bernard Burgeois, Michael Dummett, Fernando Inciarte, Christine M. Korsgaard, Ralph McInerny, Robert B. Pippin, Robert Spaemann, Franco Volpi y Wolfgang Wieland, que merecen una relectura atenta con motivo de este aniversario. Se trata de una brillante selección internacional con una notable amplitud temática.

Agradezco de todo corazón la invitación del Consejo de Redacción a presentar brevemente este volumen. 
ESTUDIOS 
